\title{
Characterization of the Interactive Effects of Glycine and D-Cycloserine in Men: Further Evidence for Enhanced NMDA Receptor Function Associated with Human Alcohol Dependence
}

\author{
John H Krystal ${ }^{*, 1,2,3}$, Ismene L Petrakis ${ }^{1,2,3}$, Diana Limoncelli ${ }^{1,2,3}$, Susan Krasnicki Nappi ${ }^{2}$, Louis Trevisan ${ }^{1,2,3}$, \\ Brian Pittman ${ }^{1,2,3}$ and Deepak C D'Souza ${ }^{1,2,3}$ \\ 'Department of Psychiatry, NIAAA Center for the Translational Neuroscience of Alcoholism, Yale University School of Medicine, New Haven, CT, \\ USA; ${ }^{2}$ VA Connecticut Healthcare System (I I -D), VA Alcohol Research Center, West Haven, CT, USA; ${ }^{3}$ Abraham Ribicoff Research Facilities, \\ Connecticut Mental Health Center, New Haven, CT, USA
}

Reduced responses to $\mathrm{N}$-methyl-D-aspartate (NMDA) glutamate receptor antagonists in alcohol-dependent animals and humans provided evidence that chronic alcohol consumption increased NMDA receptor function. To further probe alterations in NMDA glutamate receptor function associated with human alcohol dependence, this study examined the interactive effects of agents acting at the glycine $e_{B}$ coagonist site of the NMDA receptor. In doing so, it tested the hypothesis that raising brain glycine concentrations would accentuate the antagonist-like effects of the glycine ${ }_{\mathrm{B}}$ partial agonist, D-cycloserine (DCS). Twenty-two alcohol-dependent men and 22 healthy individuals completed 4 test days, during which glycine $0.3 \mathrm{~g} / \mathrm{kg}$ or saline were administered intravenously and DCS I000 mg or placebo were administered orally. The study was conducted under double-blind conditions with randomized test day assignment. In this study, DCS produced alcohol-like effects in healthy subjects that were deemed similar to a single standard alcohol drink. The alcohol-like effects of DCS were blunted in alcohol-dependent patients, providing additional evidence of increased NMDA receptor function in this group. Although glycine administration reduced DCS plasma levels, glycine accentuated DCS effects previously associated with the NMDA receptor antagonists, ketamine and ethanol. Thus, this study provided evidence that raising glycine levels accentuated the NMDA receptor antagonist-like effects of DCS and that alcohol-dependent patients showed tolerance to these DCS effects. Neuropsychopharmacology (20II) 36, 70I-7I0; doi:I0.1038/npp.20 10.203; published online I December 2010

Keywords: glycine; D-cycloserine; NMDA receptor; alcohol dependence; ethanol; learning and memory

\section{INTRODUCTION}

Ethanol dependence and the heritable risk for alcoholism are associated with the upregulation of $N$-methyl-Daspartate (NMDA) glutamate receptor function (Krystal et al, 2003c). Although ethanol is a relatively weak NMDA receptor antagonist, relative to its low affinity at other sites, its actions at this site contribute to its intoxicating effects in animals and in humans (Grant and Lovinger, 1995; Krystal et al, 2003b). In animals, chronic ethanol administration increases the gene expression and protein levels for NMDA receptor subunits, increasing the NMDA-receptor-mediated

*Correspondence: Dr JH Krystal, Department of Psychiatry, NIAAA Center for the Translational Neuroscience of Alcoholism, Yale University School of Medicine, 300 George Street, Suite 90I, New Haven, CT 065 II, USA, Tel: + I 2037856396 or + I 2039374790 , Fax: + I 203785 6196, E-mail: john.krystal@yale.edu Received 2 June 20 10; revised 21 October 2010 ; accepted 22 October 2010 neuronal response to glutamate (Hoffman, 2003; Krystal et al, 2003b; Kumari and Ticku, 2000). Consequences of this upregulation include tolerance to the effects of ethanol, features of the ethanol abstinence syndrome, increased cortical excitability and withdrawal seizures, and withdrawal-related neurotoxicity. In animals and in humans, drugs that block NMDA glutamate receptors or reduce glutamate release appear to be effective pharmacological strategies for suppressing the ethanol abstinence syndrome (Bienkowski et al, 2001; Hoffman et al, 1992; Krupitsky et al, 2007b).

The human data supporting the role of NMDA glutamate receptors in ethanol intoxication, tolerance, and dependence primarily derive from the study of subanesthetic administration of the clinically available uncompetitive NMDA receptor antagonists, ketamine, memantine, and dextromethorphan (Bisaga and Evans, 2004; Krystal et al, 2003a, 1998b; Schutz and Soyka, 2000). These drugs produce ethanol-like subjective effects in healthy individuals and 
alcohol-dependent patients. In these patients, the cognitive and behavioral effects of ketamine and dextromethorphan are substantially blunted, suggestive of the development of cross-tolerance between ethanol and ketamine. One challenge to the inference that NMDA receptor function contributes to human ethanol intoxication and dependence is the limited selectivity of these agents for NMDA receptors.

The primary aim of this study was to determine whether a drug that reduced NMDA glutamate receptor function via a distinct mechanism, reducing the activation of NMDA receptors via the glycine ${ }_{B}$ coagonist site, would yield similar inferences as did studies of the uncompetitive receptor antagonists with regard the role of NMDA receptors in ethanol intoxication and dependence. For this purpose, we chose to study D-cycloserine (DCS), the only clinically available drug with glycine ${ }_{\mathrm{B}}$ partial agonist activity. DCS has approximately $50 \%$ of the intrinsic activity of glycine, the full agonist, at the glycine $\mathrm{B}_{\mathrm{B}}$ site (Emmett et al, 1991; Hood et al, 1989; Watson et al, 1990). In animals, the behavioral effects of DCS fully generalize to those of (+)-HA966, a drug with high affinity and sufficiently low intrinsic activity for the glycine ${ }_{B}$ site to be used as an antagonist of this site (Witkin et al, 1995). However, because of the limited capacity of DCS to reduce NMDA receptor function, we sought a strategy to accentuate its glycine ${ }_{\mathrm{B}}$ antagonist-like effects. In published studies (Emmett et al, 1991; Hood et al, 1989; Watson et al, 1990), the NMDA receptor antagonistlike effects of DCS are potentiated by increasing the dose of DCS and by raising the surrounding level of glycine. Combining these two strategies produces antagonist-like effects at NMDA receptors, because under these conditions, DCS displaces glycine from glycine $_{B}$ sites, rather than stimulating unoccupied glycine ${ }_{B}$ sites. Therefore, in this study, we compared the interactive effects of high dose $(0.3 \mathrm{~g} / \mathrm{kg}$, i.v.) glycine and DCS (1000 mg, p.o.) in healthy humans and recently detoxified alcohol-dependent patients.

\section{SUBJECTS AND METHODS}

\section{Patients}

Patients who met the diagnostic criteria for ethanol dependence as determined by the Structured Clinical Interview for DSM-IV participated in testing (Spitzer et al, 1992). Patients were sober for at least 14 days before their first test day. Of the 22 patients in this study, 18 (78\%) met the von Knorring et al (1985) criteria for type 2 alcoholism, defined as the age of onset before 25 years of age and two or more social consequences of alcoholism. Of the 22 patients, 19 (86\%) had a first-degree relative with a history of alcohol dependence determined by clinical history. Patients were medically stable at study entry based on medical history, physical examination, and routine laboratory testing. Patients were excluded if they met the criteria for substance use disorder other than nicotine dependence in the year before testing. Cigarette smoking data were available on 16 of the patients. Of the 16 patients, 13 (81\%) were habitual smokers. The absence of other current substance abuse was supported by negative results of urine toxicological screens before testing. Subjects were excluded if they had another
DSM-IV axis I diagnosis during a period that was free of alcohol consumption.

Patients in this study were in outpatient treatment for alcohol dependence at the Substance Abuse Treatment Unit at VA Connecticut Healthcare System, West Haven Campus, or completing medication-free inpatient detoxification at the Abraham Ribicoff Research Facility of the Connecticut Mental Health Center (CMHC), New Haven, CT. They received treatment for the duration of the study and their treatment was not contingent upon their participation in this study. Following participation in this study, patients were followed as outpatients in the VA Substance Abuse Clinic. Twenty-seven patients signed consent forms. From this group, 20 completed 4 test days, two completed 2 test days, one completed 1 test day and four withdrew from study before their first test day. All patients were male with a mean age of $43.6 \pm 9.5$ years (SD). In the month previous to testing, the total alcohol consumption among patients was $351 \pm 229$ standard deviation (SD).

\section{Healthy Subjects}

Comparison subjects were recruited by public advertisement and were compensated for their participation. They were selected after a brief structured interview that excluded individuals with a lifetime history of a DSM-IV axis I diagnosis (Spitzer et al, 1990), history of consultation for an emotional difficulty, or psychiatric illness or alcoholism in a first-degree relative. Subjects were free of substance use disorder, other than nicotine dependence, as confirmed by urine toxicology results at the initial screening and on test days. Subjects refrained from consuming psychoactive substances, including caffeine-containing foods and beverages for 2 weeks before testing and until the last test day was completed. Subjects were free of medical illness as indicated by a medical history review, physical examination, and results of routine laboratory tests. A total of 30 subjects signed consent forms. From this group, 22 completed 4 test days, two completed 3 test days, two completed 1 test day and four withdrew from study before starting test day. The mean age of the healthy subjects was $31.9 \pm 10$ years (SD). The majority of subjects were male $(n=17,71 \%)$ and nonsmokers $(n=22,96 \%)$. In the month before testing, the total alcohol consumption among the subjects was $4.8 \pm 5.4$ standard drinks.

\section{Testing Procedure}

This research protocol was approved by the Human Subjects Subcommittee of the VA Connecticut Healthcare System (West Haven, CT) and the Human Investigation Committee of the Yale University School of Medicine (New Haven, CT). After giving informed consent, each participant completed 4 test days separated by 3-7 days in a randomized order under double-blind conditions: placebo DCS and glycine; DCS and placebo glycine; DCS and glycine; and placebo DCS and placebo glycine. The drugs were administered in a fixed order with DCS $(1000 \mathrm{mg})$ or matched placebo given $4 \mathrm{~h}$ before the 30-min glycine infusion $(0.3 \mathrm{~g} / \mathrm{kg})$. Before testing, participants fasted overnight and they remained in a fasting state during the test 
session. They presented for testing at approximately 0800 hours and an intravenous line was placed at that time.

Subjective intoxication was assessed using the Likert scales (0-7 scale) of high and similarity to alcohol. The Number of Drinks Scale asks subjects to report on the number of ethanol drinks they felt they had consumed. The Biphasic Alcohol Effects Scale (BAES) is a 14-item scale (0-10 scale), with seven items designed to assess stimulant effects associated with the ascending limb of ethanol intoxication and seven items developed to measure sedative effects associated with the descending limb of ethanol intoxication (Martin et al, 1993). These scales were completed at 240 and $60 \mathrm{~min}$ before the glycine infusion and at the 30,60, and 120 min post-infusion time points. Alcohol craving was assessed using a $100 \mathrm{~mm}$ visual analog scale. There were no effects of glycine, DCS, or their combination on craving in this study and so detailed craving results are not presented.

Cognitive effects were assessed with the Hopkins Verbal Learning Task (HVLT) and a continuous performance task (CPT). The HVLT is a word list learning test of verbal memory (Brandt, 1991). This test is sensitive to the amnesic effects of NMDA antagonists and has the advantage of six different versions that permit multiple episodes of testing. The procedures associated with the test allow some degree of distinction between immediate recall, delayed recall, and recognition. The HVLT was administered 60 min postglycine infusion. Vigilance to visual stimuli was measured by using the A' score derived from the CPT (Gordon, 1983), in which subjects attended to numbers that were presented sequentially on a screen. The subjects pushed a button to signal when a ' 9 ' was preceded by a ' 1 '. The distractibility task was identified to the vigilance task, with the exception that numbers were presented sequentially in three contiguous columns. Subjects had to attend to the middle column and ignore the numbers presented in the outer two columns. The CPT was administered once per test day at 30 min post-glycine infusion.

Perceptual changes resembling dissociative states were assessed using the Clinician-Administered Dissociative States Scale (Bremner et al, 1998). The Alcohol Craving Scale consisted of four Likert-type scales (0-100 scale; in dividends of 10) evaluating dimensions of alcohol craving explored in previous studies (Krystal et al, 1998b, 1994).

Plasma DCS levels were determined using a published validated liquid chromatographic procedure using benzoquinone as a derivatizing reagent (David et al, 2001). Briefly, $0.5 \mathrm{ml}$ of $p$-benzoquinone $(1 \mathrm{mg} / \mathrm{ml})$ was added to $0.25 \mathrm{ml}$ of plasma and allowed to react at room temperature. Following centrifugation for $15 \mathrm{~min}$, the supernatant was transferred to the liquid chromatograph and $5 \mu \mathrm{l}$ injected on a reversed-phase octadecylsilyl (C-18) column eluted with an acetic acid, methanol, and acetonitrile mobile phase at a flow rate of $1.0 \mathrm{ml} / \mathrm{min}$. A fluorescence detector set at $350 \mathrm{~nm}_{\text {excit. }}$ and $510 \mathrm{~nm}_{\text {emiss. }}$ was used to monitor the separated peaks. A six-point calibration curve and three quality controls in duplicate were included with each set of samples. Chromatographic data was collected using a PC-based chromatography software program. Intra-day variation did not exceed $10.8 \%$ for all six calibration levels ( $n=12$ each), and inter-day variation based on the quality control data did not exceed 9.2\% ( $n=9$ consecutive days).
Plasma glycine levels were assayed using a modified liquid chromatographic procedure using O-methylserine as the internal standard (Hariharan et al, 1993). Plasma $(0.25 \mathrm{ml})$ was deproteinized and extracted before derivatization with PITC reagent to enhance separation and detection at $254 \mathrm{~nm}$. Calibration standards that included the expected concentration range for this study preceded each batch of samples as well as a set of quality controls to validate each day's analyses. Inter-assay variability for glycine was 7.3\% for the low quality control and $5.9 \%$ for the high quality control ( $n=28$ consecutive days). On the basis of previous data, intra-assay variability for glycine is $1.2 \%$ for the low quality controls and $3.0 \%$ for the high quality controls $(n=12$ replicates).

\section{Data Analysis}

Initially, data were examined descriptively using means, standard deviations, and graphs. Each outcome was tested for normality using Kolmogorov-Smirnov test statistics and normal probability plots. All outcomes, except for Hopkins immediate recall data, were highly skewed and non-normal, even after transformation. Non-normal outcomes were analyzed using the non-parametric approach for repeated measures data (Brunner et al, 2002), wherein the data were first ranked, and then fitted using a mixed-effects model with an unstructured variance-covariance matrix and $p$-values adjusted for ANOVA-type statistics (ATS). In these models, DCS (placebo $v s$ active), glycine (placebo $v s$ active), and time (see study time points) were included as withinsubject explanatory factors, whereas diagnostic group (healthy $v s$ alcoholics) was included as a between-subjects factor. All multiway interactions were fitted. Subgroup analyses within each diagnostic group were performed when significant interactions with diagnosis were present. When appropriate, post hoc comparisons were performed. In the above models, subject was used as the clustering factor. Hopkins' immediate recall data was analyzed using a linear mixed model with within-subject factors of DCS, glycine, and trial (1-3), a between-subjects factor of diagnostic group, as well as a random subject effect. The correlation structure within each individual was modeled with a random subject effect and structured variance-covariance matrix within day within subject. The best fitting correlation structure was selected according to Akaike information criterion and Schwartz Bayesian criterion. Plasma DCS, glycine, and $\mathrm{D} / \mathrm{L}$-serine levels were analyzed using linear mixed models with DCS or glycine, accordingly, and time as within-subject factors, as above. In the above models, age was considered as a covariate, but was not significant in any model and dropped for parsimony. Post hoc comparisons were adjusted for multiple comparisons using the Bonferonni correction within but not across domains. All available data on each subject were used in the analyses described above using PROC MIXED in SAS, version 9.1 (Cary, NC).

\section{RESULTS}

\section{Subjective Effects of DCS and Glycine}

Similarity to ethanol effects. The similarity of DCS and glycine effects to ethanol is reported in Figure 1. Analysis of 

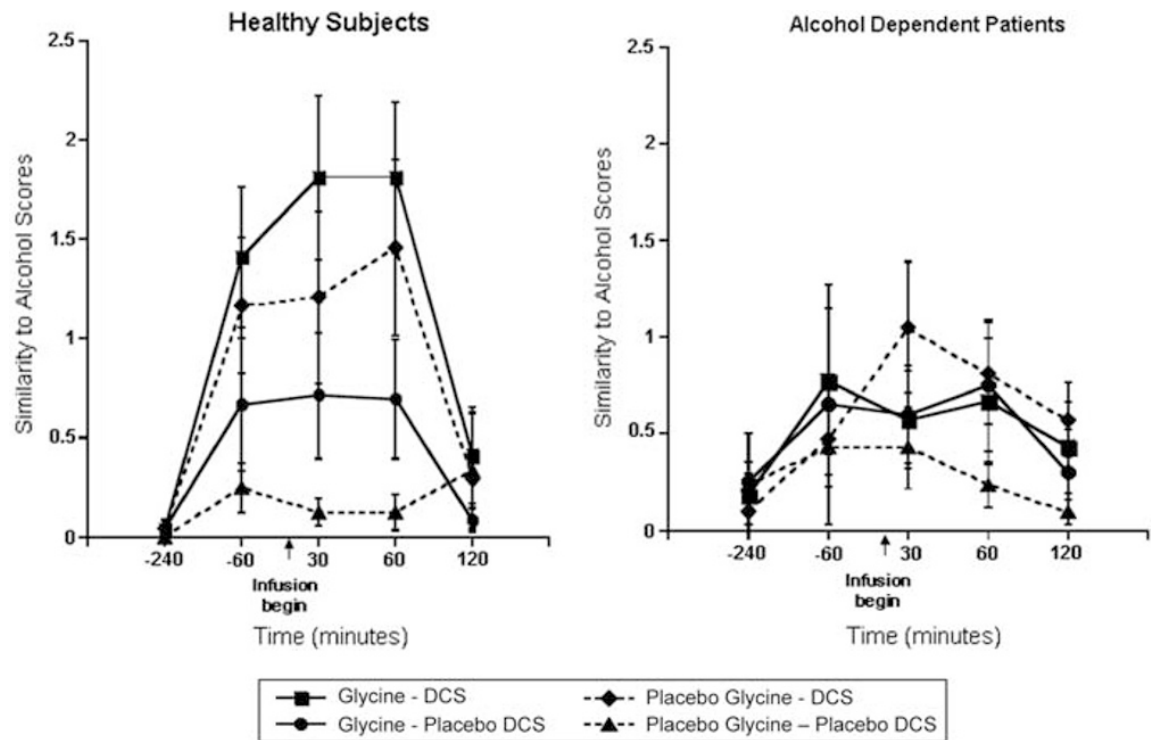

Figure I Similarity to alcohol. DCS was administered at $240 \mathrm{~min}$ before the infusion of glycine or saline.

the data using the Likert scale (0-7 scale) evaluating the similarity of drug effects to ethanol indicated that there were significant interactive effects of DCS, time, and diagnosis $(\mathrm{ATS}=4.76 ;$ num $\mathrm{df}=3.56 ; p=0.0013)$. This interaction was explained by significant ethanol-like effects of DCS in healthy subjects (DCS by time interaction: ATS $=7.21$; num df $=3.29 ; p<0.0001)$ that were not significant in patients. Similarly, glycine produced ethanol-like effects in healthy subjects that were relatively weak (glycine by time interaction: ATS $=2.69$; num $\mathrm{df}=2.96$; $p=0.045)$. In healthy subjects, glycine and DCS appeared to have additive effects as there was no statistical interaction between DCS, glycine, and time, but the combination of glycine and DCS produced effects that were more similar to ethanol than DCS alone (ATS $=9.1$; num $\mathrm{df}=1 ; p=0.003$ ).

\section{Intensity of Ethanol-like Effects}

Number of Drinks Scale. DCS produced effects that subjects deemed similar to the effect of a standard ethanol drink (Figure 2). In the analysis of the subjective number of drinks consumed, data of the subjective number of drinks consumed show that there was a significant interaction observed between glycine, DCS, and diagnosis (ATS $=3.92$; num $\mathrm{df}=1 ; p=0.048)$. Subgroup analysis determined an increased perception of the number of drinks consumed owing to DCS among healthy subjects (DCS by time interaction: $\mathrm{ATS}=4.18$; num $\mathrm{df}=2.56 ; p=0.009$ ), but not in patients (FYI: DCS by time interaction: $\mathrm{ATS}=0.68$; num $\mathrm{df}=2.78 ; p=0.55)$. Although the interaction between glycine, DCS, and time was not significant in healthy subjects, glycine and DCS appeared to have additive effects as the combination of the two drugs trended toward increased perception of the number of drinks consumed compared with glycine alone $(\mathrm{ATS}=3.69$; num $\mathrm{df}=1$; $p=0.055$ ).

Biphasic Alcohol Effects Scale. There were no statistically significant drug effects upon the stimulant subscale of the
BAES. However, for the sedative subscale of the BAES (Figure 3), there were significant interactions of DCS and time (ATS $=5.37 ;$ num $\mathrm{df}=3.31 ; p=0.0007$ ) and time by diagnosis $(\mathrm{ATS}=6.41$; num $\mathrm{df}=3.22 ; p=0.0002)$. To better understand these two highly significant results, we analyzed the groups separately. There were significant ethanol-like effects of DCS in healthy subjects (DCS by time interaction: ATS $=5.81 ; \quad d f=3.45 ; p=0.0003)$, but not in patients (ATS $=0.39 ;$ num $\mathrm{df}=3.59 ; p=0.79)$. There were no significant interactive effects of glycine and DCS on this dependent measure.

High. In the analysis of the Likert scale (0-7 scale) data assessing the subjective state of 'high' (presented in Figure 4), there was a significant interaction between DCS, time, and diagnosis (ATS $=2.86$; num $\mathrm{df}=3.65 ; p=0.026$ ). In the subgroup analysis, there were significant ethanol-like effects of DCS in healthy subjects (DCS by time interaction: ATS $=3.53$; num $\mathrm{df}=3.53 ; p=0.0097)$, but not in patients (ATS $=0.32 ;$ num $\mathrm{df}=3.42 ; p=0.83$ ). There were no significant interactive effects of glycine and DCS for this dependent measure.

Alcohol Craving Scale. Alcohol craving was present in patients, but not healthy in subjects, reflected in an increased scores on the subscale measuring desire to drink (diagnosis: $\mathrm{ATS}=3.85 ; \mathrm{df}=1 ; p=0.05$ ), the subscale measuring expected alcohol-related mood improvement (diagnosis: $\mathrm{ATS}=7.4 ; \mathrm{df}=1 ; \quad p=0.007$ ), the subscale reflecting expected alcohol-related relief from discomfort (diagnosis: $\mathrm{ATS}=7.1 ; \mathrm{df}=1 ; p=0.008$ ), and the scale measuring reduced control of alcohol use (diagnosis: $\mathrm{ATS}=82.4 ; \mathrm{df}=1 ; p<0.0001)$. However, there were no significant effects of DCS or glycine or significant interactions with time or diagnosis effects on these measures.

Clinician-Administered Dissociative States Scale. There was no significant interaction of DCS, glycine, and diagnosis effects on this measure. 


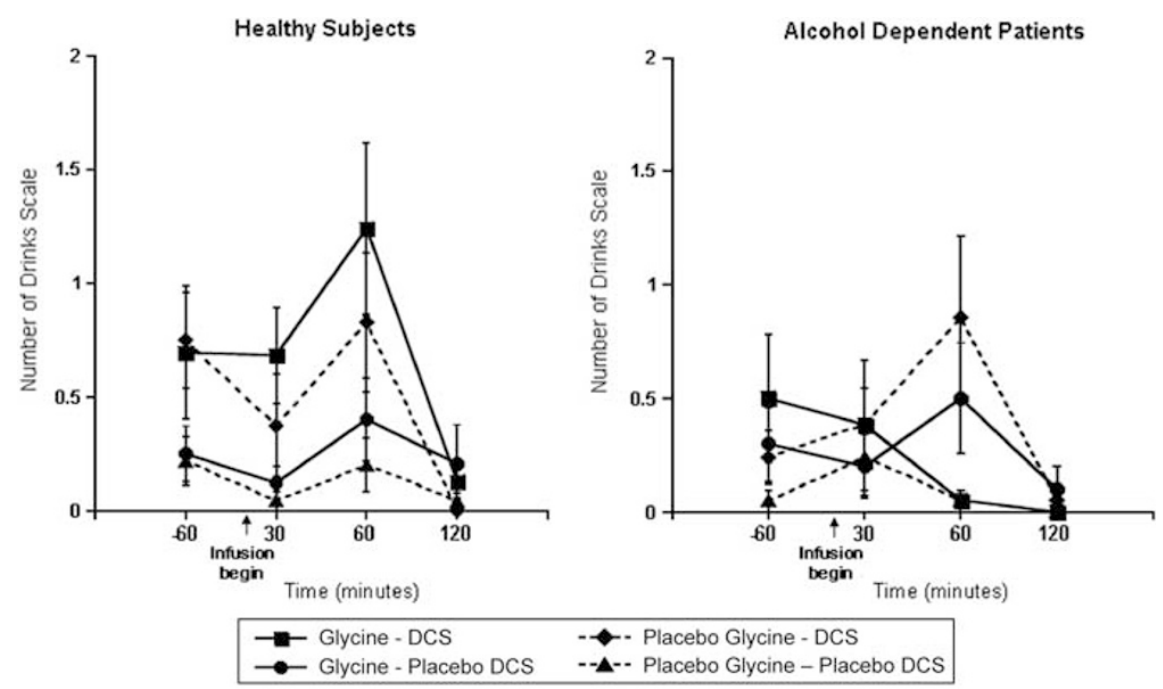

Figure 2 Number of Drinks Scale (NDS). DCS was administered at $240 \mathrm{~min}$ before the infusion of glycine or saline.
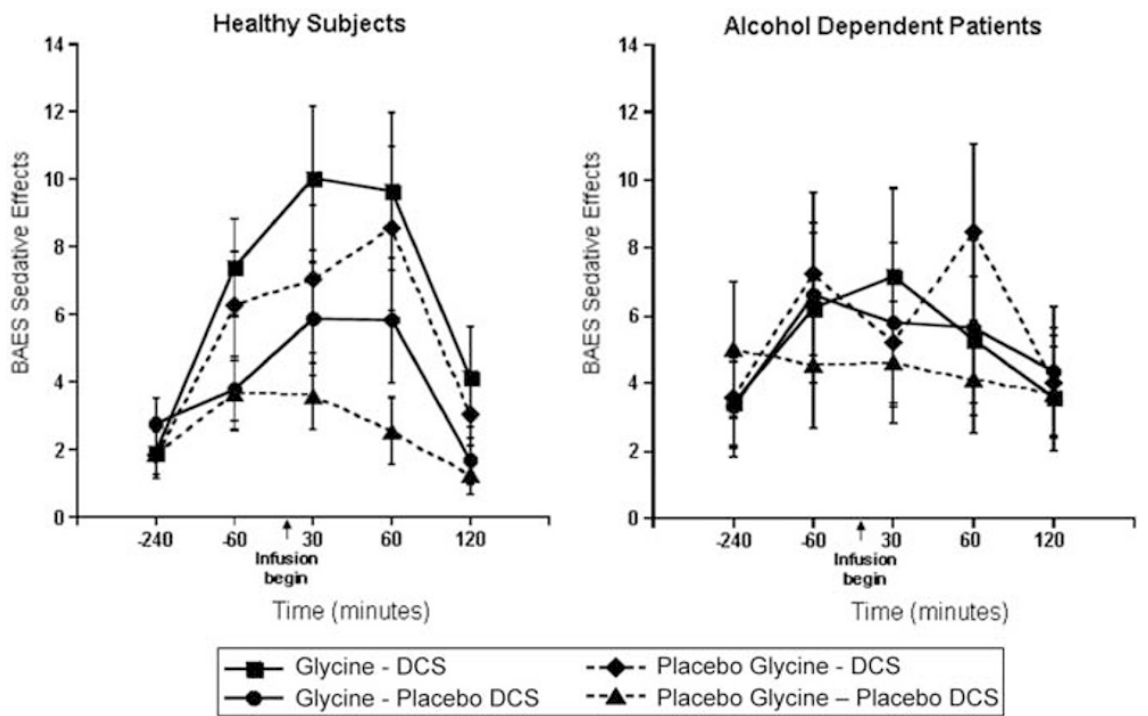

Figure 3 Biphasic Alcohol Effects Scale (BAES) Sedative Subscale. DCS was administered at 240 min before the infusion of glycine or saline.

\section{Cognitive Effects of DCS and Glycine}

Effects of DCS and glycine on a CPT evaluating vigilance and distractibility. There were no statistically significant effects of DCS, glycine, or the combination of these substances on vigilance or distractibility in healthy subjects. There was a clinically trivial, but statistically highly significant reduction in vigilance task $A^{\prime}$ scores associated with the combination of DCS and glycine in the alcoholdependent patients (DCS by glycine by diagnosis interaction: ATS $=7.97 ; \mathrm{df}=1 ; p=0.0048)$ and poorer overall A' scores in the patient group (diagnosis: $\mathrm{ATS}=11.85 ; \mathrm{df}=1 ; p=0.0006$ ) (Figure 5). In patients, but not healthy subjects, DCS worsened vigilance, but only in the context of administration with glycine. With regards to distractibility, there was a small, but highly significant increase in distractibility in the patients as reflected by reduced A' scores (diagnosis: ATS $=20.71$; $\mathrm{df}=1 ; p<0.0001$ ), but no pharmacological effects were significant after adjusting for multiple comparisons.

\section{Amnestic Effects as Detected by the HVLT}

Working memory. The analysis of the three immediate recall trials revealed that patients performed more poorly than healthy subjects $(\mathrm{F}(1,463)=47.7, p<0.0001)$, DCS impaired memory across the trials $(\mathrm{F}(1,463)=36.6$, $p<0.0001)$, and immediate recall scores improved over the three repetitions $(\mathrm{F}(2,463)=401.4, p<0.0001)$. However, there were no interactions among these main effects (Figure 6) and no impact of co-varying for scores on the self-rated Likert scale (0-7 scale) measuring drowsiness. Healthy subjects showed significant DCS $(\mathrm{F}(1,247)=$ $16.4, p<0.0001)$ and repetition trial $(\mathrm{F}(2,247)=201.4$, $p<0.0001)$ effects. In healthy subjects, the glycine test day results were not significantly different than the saline test day results $(F(1,247)=1.47, p=0.23)$. However, the combination of glycine and DCS produced greater reduction in immediate recall than did DCS alone $(\mathrm{F}(1,247)=3.95$, $p=0.048)$. Patients showed similar effects for DCS 

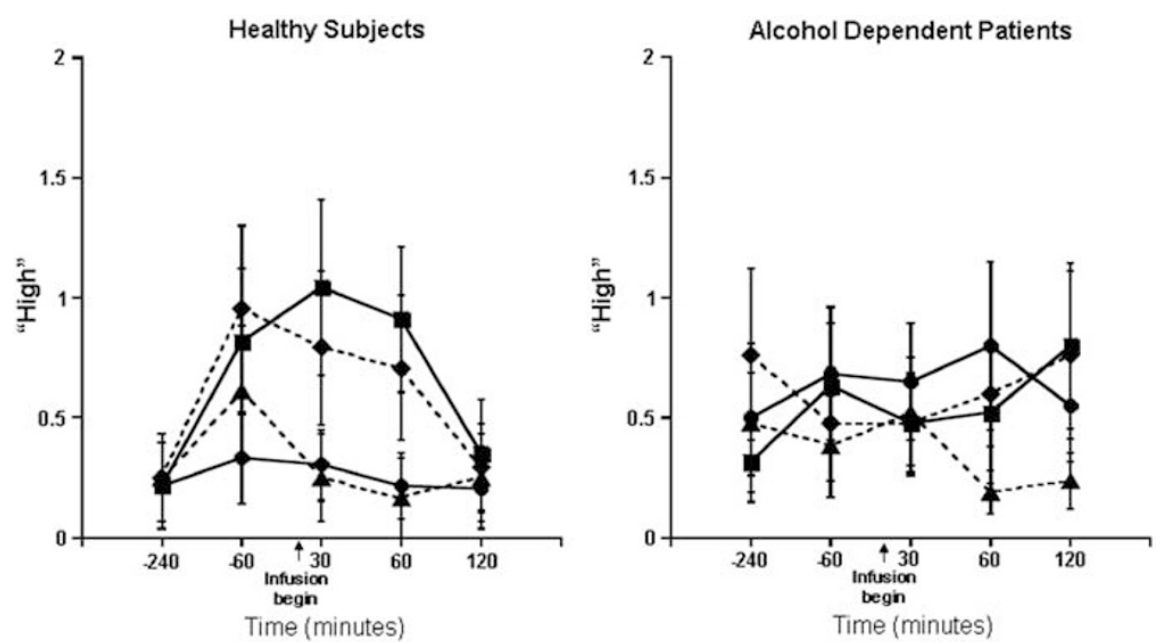

Glycine - DCS

Glycine - Placebo DCS

- - Placebo Glycine - DCS

--A-- Placebo Glycine - Placebo DCS

Figure 4 Likert scale 'High'. DCS was administered at $240 \mathrm{~min}$ before the infusion of glycine or saline.

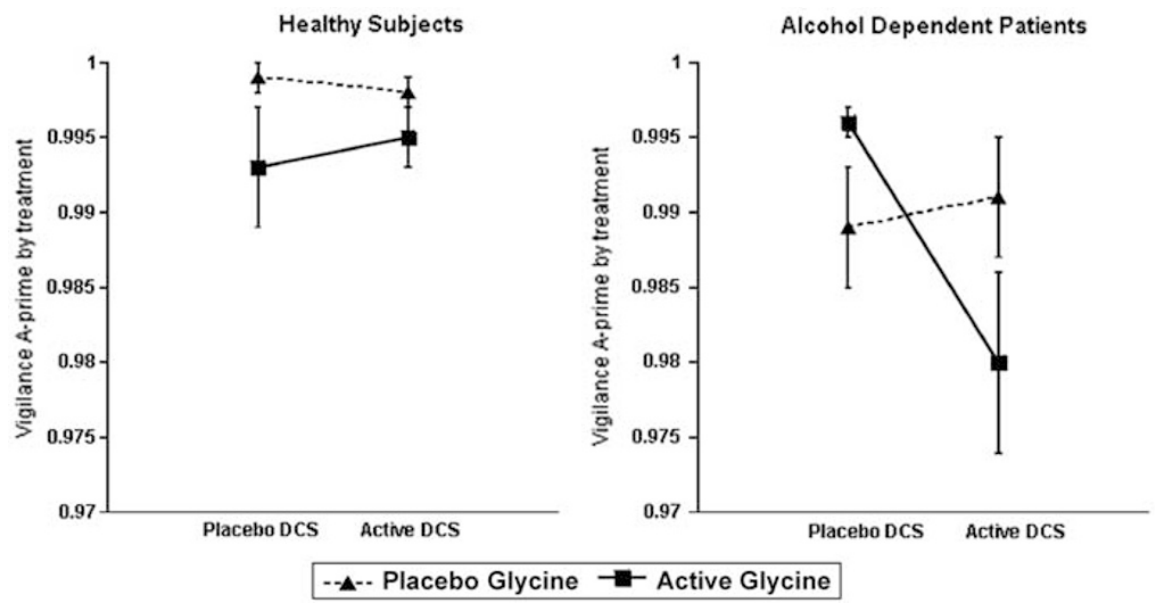

Figure 5 Continuous performance task of vigilance, A' score. D-Cycloserine (DCS) was administered at 240 min before the infusion of glycine or saline.
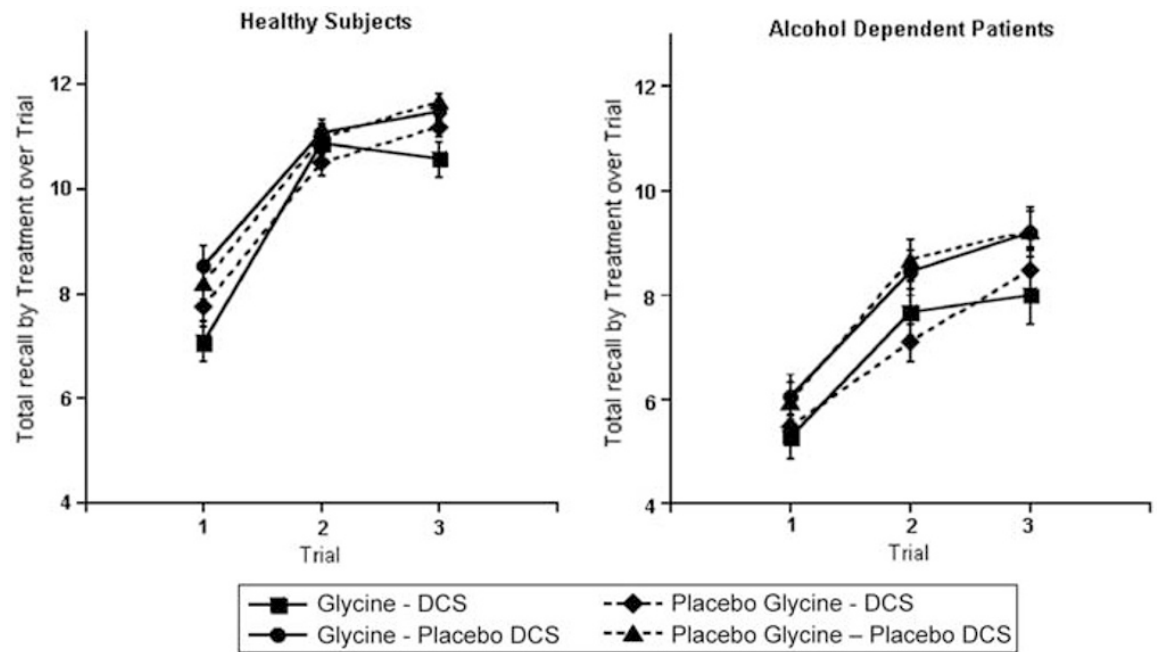

Figure 6 Immediate recall Hopkins Verbal Learning Task (HVLT) scores. DCS was administered at 240 min before the infusion of glycine or saline. 


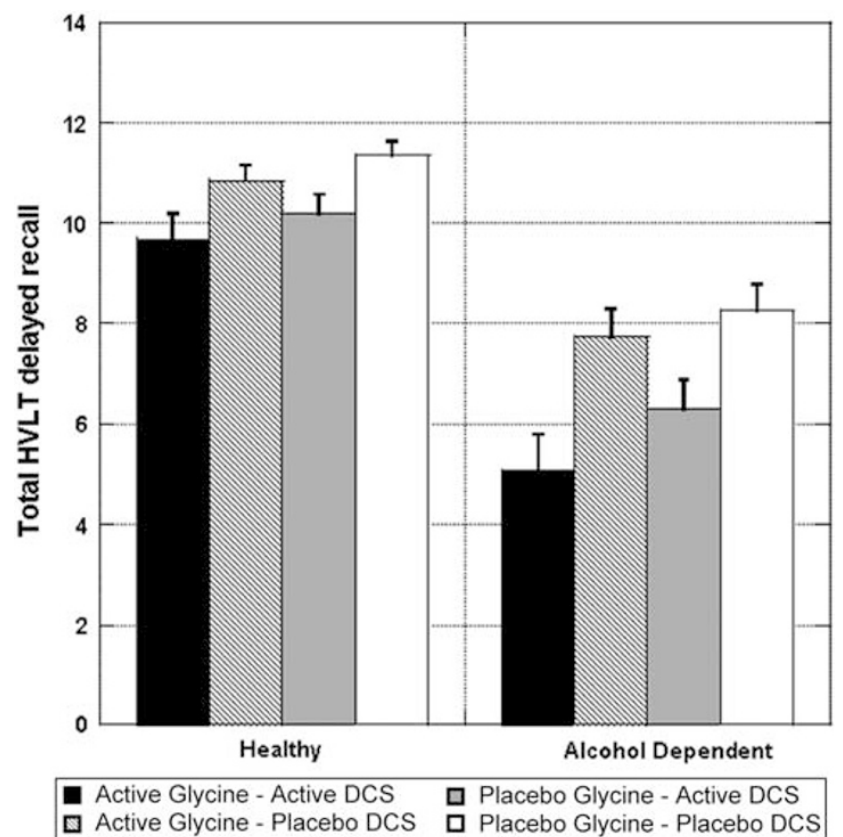

Figure 7 Total delayed recall Hopkins Verbal Learning Task (HVLT) scores by treatment and diagnosis. DCS was administered at $240 \mathrm{~min}$ before the infusion of glycine or saline.

$(\mathrm{F}(1,216)=17.9, p<.0001)$, but glycine did not accentuate the effects of DCS $(\mathrm{F}(1,216)=0.02, p=0.88)$.

Delayed recall. The analysis of delayed recall data (Figure 7) revealed that patients performed more poorly than did healthy subjects (ATS $=60.7$; num $\mathrm{df}=1 ; p<0.0001$ ) and DCS impaired delayed recall $(\mathrm{ATS}=35.1 ; \mathrm{df}=1$; $p<0.0001$ ), with no interactions between these effects. Adjusting for performance on the third immediate recall trial or for drowsiness did not affect these findings. In healthy subjects, the DCS effect on delayed recall was not significant after adjusting for performance on the third immediate recall trial (ATS $=3.44$; num $\mathrm{df}=1 ; p=0.06$ ), suggesting that it may not have had a significant effect on memory consolidation. However for patients, this amnestic effect of DCS remained significant after adjusting for the third immediate recall trial $(\mathrm{ATS}=14.8$; num $\mathrm{df}=1 ; p<0.0001)$. There were no significant interactive effects of glycine and DCS on delayed recall scores in either group.

\section{Plasma Levels of DCS, Glycine, and D/L-Serine}

Glycine administration substantially raised plasma glycine levels $(\mathrm{F}(3,295)=303.24, p<0.0001)$ (see Figure 8). However, plasma glycine levels increased to a similar extent when glycine was administered by itself or in combination with DCS. Although glycine administration did not reduce the effects of DCS on any dependent measure, DCS (substance by time interaction: $\mathrm{F}(2,73)=8.14 ; p=0.0006$ ) and $\mathrm{D} / \mathrm{L}$-serine (substance by time interaction: $\mathrm{F}(3,295)=$ 3.35; $p=0.019$ ) plasma levels were significantly lower on days when glycine, rather than placebo, was infused.
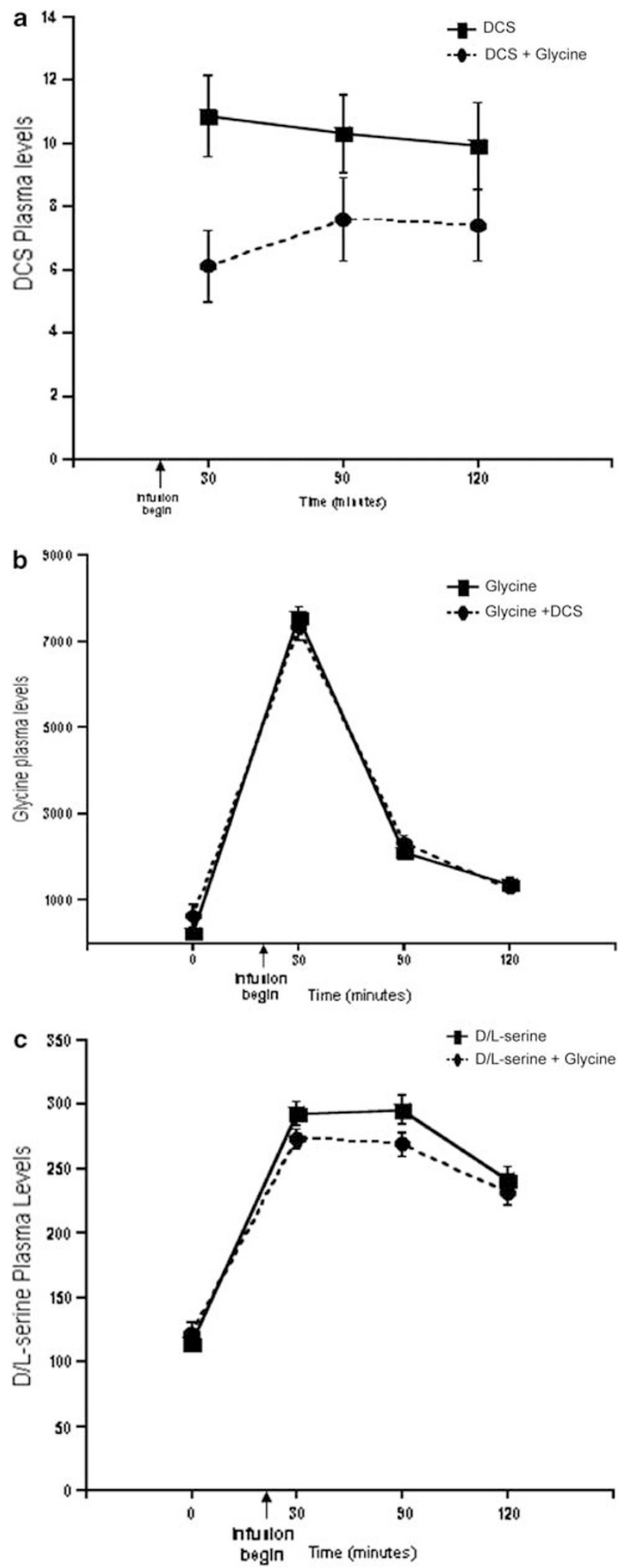

Figure 8 Plasma levels of D-cycloserine (DCS), glycine, and D/L-serine. (a) Plasma DCS levels over time by treatment. (b) Plasma glycine levels over time by treatment. (c) Plasma D/L-serine levels over time by treatment. D/L-serine + glycine. DCS was administered at 240 min before the infusion of glycine or saline. 


\section{DISCUSSION}

The principal findings of this study were that DCS $1000 \mathrm{mg}$ produced subjective effects that were similar to the effects of one standard ethanol drink, a finding previously reported for low doses of NMDA receptor antagonists (Dickerson et al, 2010; Krystal et al, 1998c). These effects were blunted in ethanol-dependent patients. Thus, the current data replicate preclinical and clinical data, indicating that the behavioral effects of glycine ${ }_{\mathrm{B}}$ site antagonists generalize to those of ethanol (Kostowski and Bienkowski, 1999; Kotlinska and Liljequist, 1997; Trevisan et al, 2008), despite a negative preclinical report for DCS (Bienkowski et al, 1997). The findings also are consistent with the evidence that DCS $500 \mathrm{mg}$ and ethanol produce additive behavioral effects in humans (Trevisan et al, 2008), perhaps related to the capacity of each drug to reduce NMDA receptor function. The blunting of DCS response in alcoholdependent patients suggests that reduced responses to NMDA receptor antagonists are not limited to uncompetitive blockers of this receptor. They also provide additional support for the hypothesis that human alcohol dependence is associated with increased NMDA receptor function (Krystal et al, 2003a).

The ethanol- and NMDA receptor antagonist-like subjective effects of DCS were increased by pretreatment with glycine $0.3 \mathrm{~g} / \mathrm{kg}$ i.v., even though glycine lowered plasma DCS levels and had very little effect on behavior by itself. The dose of glycine administered in this study produced plasma levels of $7500 \mu \mathrm{mol} / \mathrm{l}, 50 \%$ higher than a previous human study where glycine infusion raised cerebrospinal fluid glycine levels approximately fivefold (D'Souza et al, 2000). Thus, this study provided preliminary support for the hypothesis that the glycine $\mathrm{B}_{\mathrm{B}}$ antagonist-like effects of DCS would be increased by raising brain glycine levels. By providing support for this interaction between glycine and DCS, this study provides the most direct in vivo human evidence to date that DCS is a partial agonist of the glycine ${ }_{B}$ site of NMDA receptors.

In alcohol-dependent patients, the ethanol-like, sedative, and euphoric effects of DCS were attenuated. However, patients had poorer attention and memory function at baseline. Building on this baseline impairment, patients exhibited greater reduction in vigilance than did healthy subjects in response to DCS and glycine. We speculate that one possible explanation for these findings is that alcoholism-related neurotoxicity in patients may have left them with less 'cognitive reserve' than healthy subjects. Cognitive reserve is a concept that has been widely applied to populations where pre-existing circuitry deficits render people more sensitive to any condition that might further compromise their cognitive function (Barnett et al, 2006; Fein and McGillivray, 2007; Stern et al, 1996). Alternatively, the increased sensitivity to the cognitive effects of glycine and DCS might be related to their agonist properties, paralleling the attribution of the reduced sensitivity to DCS effects to its antagonist-like effects. In a previous study, a low dose of ketamine tended to improve performance on the Wisconsin Card Sorting Test in a similar group of recently detoxified alcohol-dependent patients (Krystal et al, 2003a). In that study, it was hypothesized that alcohol dependence-related upregulation of NMDA receptor function might result in network hyperactivity. In this state, low doses of ketamine suppressed this symptom of protracted ethanol withdrawal without producing additional impairment. Glycine has regionally selective effects in the brain that presumably reflect differences in regional NMDA receptor subunit composition and localization (Gonzales and Brown, 1995). The upregulation of NMDA receptor subunits produced by chronic ethanol administration is greater for NR1, NR2A, and NR2C subunits than for NR2D subunits, with some brain regional variation (Allgaier et al, 1999; Darstein et al, 2000). DCS is a partial agonist for NMDA receptors bearing the NR1 subunit combined with the NR2A and NR2B subunits, but it is a potent full agonist for receptors bearing the NR1 subunit combined with the NR2C and NR2D subunits (Danysz and Parsons, 1988; Krueger et al, 1997; Sheinin et al, 2001). A parsimonious hypothesis, therefore, is that glycine and DCS worsened memory function in alcohol-dependent patients by enhancing NMDA receptor function in circuits where NMDA receptors were already upregulated, perhaps via NMDA receptors containing NR2C or NR2D subunits.

A number of issues limit inferences that might be drawn from this study. First, it would have been preferable to study a glycine $_{\mathrm{B}}$ site antagonist, rather than a partial agonist. The low activity of DCS at NR2B-containing NMDA receptors, approximately $35 \%$ that of glycine in oocytes (Sheinin et al, 2001), suggests that NMDA antagonist-like effects might be mediated particularly by these receptors. However, the complex dose- and NMDA receptor subtype-related effects of DCS make inferences drawn from the observed glycine and DCS interactions somewhat speculative. Although not accessible to this research team, it would have been preferable to study the interaction of glycine with a selective glycine $_{\mathrm{B}}$ antagonist. Second, our efforts to study the antagonist-like effects of DCS necessitated our studying relatively a relatively high dose of this drug. We felt justified in studying this dose because our previous studies and pilot data with $50,100,250,500$, and $1000 \mathrm{mg}$ showed doserelated antagonist-like effects for several of the dependent measures reported in this study (Barr et al, 1994; D'Souza et al, 2000; Krystal et al, 1998a; Trevisan et al, 2008). Although the pharmacology of DCS at sites other than the glycine $_{\mathrm{B}}$ site are not well understood, studying higher doses raises concerns about receptor selectivity. Third, although based on preclinical data and our previous studies, it is not clear that we have optimized the doses of DCS and glycine to observe the hypothesized interaction. Fourth, this study could not independently evaluate the impact of alcohol dependence and a family history of alcoholism. Thus, there is risk of attributing altered DCS responses to neuroadaptations to ethanol when they might reflect the heritable risk for alcoholism. Reduced ketamine responses were observed in healthy subjects with a family history of alcoholism (Petrakis et al, 2004), heightening this concern. However, the familial risk for alcoholism does not appear to be related to variation in the gene coding for glycine transporter-1, the protein most directly responsible for controlling synaptic glycine levels (Koller et al, 2009). Also, in our previous study, patients with and without family histories of alcoholism revealed a similar pattern of alteration in ketamine response, with a non-significant trend for greater blunting of ketamine response in those patients with a family history 
of alcohol dependence (Krystal et al, 2003a). Similarly, in this study, the groups were not matched for smoking. Although nicotine dependence did not substantially alter the pattern of ketamine effects in previous studies, it remains a concern related to the findings reported here. Also, this study was limited to men and the pattern of finding may not generalize to women who show subtle reductions in ketamine response compared to men (Morgan et al, 2006). Lastly, glycine reduced DCS plasma levels and this effect may have blunted the effects associated with the combined administration of DCS and glycine.

In conclusion, this study provides further human evidence that altered NMDA receptor function is associated with human alcohol dependence. To date, NMDA receptor antagonists have produced mixed results in treatment studies for alcohol dependence. Acamprosate, initially thought to reduce drinking via blockade of NMDA receptors (Rammes et al, 2001), may not achieve adequate levels in the brain with oral administration to have functional activity at this site. Memantine appears to suppress alcohol withdrawal symptoms and cue-induced craving for ethanol in humans (Krupitsky et al, 2007a,b), but it may be ineffective in reducing drinking for many patients (Evans et al, 2007). DCS might be a candidate for therapeutic trials for alcoholism. By virtue of its partial agonist effects, it may be a more tolerable strategy for reducing NMDA receptor function than uncompetitive antagonists that block most NMDA receptor subtypes. Alternatively, the efficacy of the glycine transporter-1 antagonist org 25935 to reduce ethanol-stimulated dopamine release within the nucleus accumbens and ethanol consumption (Lido et al, 2009; Molander et al, 2007) suggests that treatments that enhance glycine ${ }_{\mathrm{B}}$ site function might also have therapeutic potential for alcoholism.

\section{ACKNOWLEDGEMENTS}

This work was generously supported by Department of Veterans Affairs (Merit Review Grant, Alcohol Research Center, Merit Review Grant, National Center for PTSD), the National Institute on Alcohol Abuse and Alcoholism (K05 AA-14906-01, I-P50 AA-12870), and the Yale Center for Clinical Investigation (CTSA). We gratefully acknowledge the critical expert contributions of the research nursing staff of the VA Connecticut Healthcare System Biostudies Unit, Ms Angelina Genovese and Ms Elizabeth O’Donnell.

\section{DISCLOSURE}

During the period 2007-2010, Dr Krystal has served as a scientific consultant to the following companies: Aisling Capital, LLC, AstraZeneca Pharmaceuticals, Brintnall \& Nicolini, Cypress Bioscience, Easton Associates, Eli Lilly and Company, F. Hoffmann-La Roche, Forest Laboratories, Gilead Sciences, Glaxo SmithKline, HoustonPharma, Lohocla Research Corporation, Lundbeck Research USA, Merz Pharmaceuticals, MK Medical Communications, Naurex, Pfizer Pharmaceuticals, Schering-Plough Research Institute, SK Holdings, Takeda Industries, Teva Pharmaceutical Industries, and Transcept Pharmaceuticals. Dr Krystal holds less than US\$500 in exercisable warrant options with Transcept Pharmaceuticals. He is the principal investigator of a multicenter study in which Janssen Research Foundation has provided drug and some support to the Department of Veterans Affairs. Dr Krystal is a cosponsor for two patents under review for glutamatergic agents targeting the treatment of depression. Dr D'Souza has been the principal investigator for studies which Yale University School of Medicine receives funding from Pfizer Pharmaceuticals, Cephalon, Abbott Laboratories, Astra Zeneca, Organon/Schering Plough, Sanofi-Aventis, and GlaxoSmithKline in the past 5 years. Dr Ismene Petrakis, Diana Limoncelli, Susan Krasnicki Nappi, Dr Louis Trevisan, and Brian Pittman declare no conflict of interest.

\section{REFERENCES}

Allgaier C, Scheibler P, Muller D, Feuerstein TJ, Illes P (1999). NMDA receptor characterization and subunit expression in rat cultured mesencephalic neurones. Br J Pharmacol 126: 121-130.

Barnett JH, Salmond CH, Jones PB, Sahakian BJ (2006). Cognitive reserve in neuropsychiatry. Psychol Med 36: 1053-1064.

Barr LC, D’Souza DC, Price LH, Krystal JH (1994). Evaluation of dose-related effects of D-cycloserine in unmedicated obsessive compulsive disorder patients. Soc Neurosci Abstr 20: 1564 (abstract no. 641.9).

Bienkowski P, Krzascik P, Koros E, Kostowski W, Scinska A, Danysz W (2001). Effects of a novel uncompetitive NMDA receptor antagonist, MRZ 2/579 on ethanol self-administration and ethanol withdrawal seizures in the rat. Eur J Pharmacol 413: 81-89.

Bienkowski P, Stefanski R, Kostowski W (1997). Discriminative stimulus effects of ethanol: lack of antagonism with $N$-methyl-Daspartate and D-cycloserine. Alcohol 14: 345-350.

Bisaga A, Evans SM (2004). Acute effects of memantine in combination with alcohol in moderate drinkers. Psychopharmacology 172: 16-24.

Brandt J (1991). The Hopkins Verbal Learning Test: development of a new memory test with six equivalent forms. Clin Neuropsychologist 5: 125-142.

Bremner JD, Krystal JH, Putnam FW, Southwick SM, Marmar C, Charney DS et al (1998). Measurement of dissociative states with the Clinician-Administered Dissociative States Scale (CADSS). J Trauma Stress 11: 125-136.

Brunner E, Domhof S, Langer F (2002). Nonparametric Analysis of Longitudinal Data in Factorial Experiments. Wiley: Hoboken, NJ.

D'Souza DC, Gil R, Cassello K, Morrissey K, Abi-Saab D, White J et al (2000). IV glycine and oral D-cycloserine effects on plasma and CSF amino acids in healthy humans. Biol Psychiatry 47: 450-462.

Danysz W, Parsons CG (1988). Glycine and N-methyl-D-aspartate receptors: physiological significance and possible therapeutic applications. Pharmacol Rev 50: 597-664.

Darstein MB, Landwehrmeyer GB, Feuerstein TJ (2000). Changes in NMDA receptor subunit gene expression in the rat brain following withdrawal from forced long-term ethanol intake. Naunyn Schmiedebergs Arch Pharmacol 361: 206-213.

David V, Ionescu M, Dumitrescu V (2001). Determination of cycloserine in human plasma by high-performance liquid chromatography with fluorescence detection, using derivatization with $p$-benzoquinone. J Chromatogr B 761: 27-33.

Dickerson D, Pittman B, Ralevski E, Perrino A, Limoncelli D, Edgecombe J et al (2010). Ethanol-like effects of thiopental and ketamine in healthy humans. J Psychopharmacol 24: 203-211.

Emmett MR, Mick SJ, Cler JA, Rao TS, Iyengar S, Wood PL (1991). Actions of D-cycloserine at the N-methyl-D-aspartateassociated glycine receptor site in vivo. Neuropharmacology 30: 1167-1171. 
Evans SM, Levin FR, Brooks DJ, Garawi F (2007). A pilot doubleblind treatment trial of memantine for alcohol dependence. Alcohol Clin Exp Res 31: 775-782.

Fein G, McGillivray S (2007). Cognitive performance in long-term abstinent elderly alcoholics. Alcohol Clin Exp Res 31: 1788-1799.

Gonzales RA, Brown LM (1995). Brain regional differences in glycine reversal of ethanol-induced inhibition of $N$-methyl-D-aspartatestimulated neurotransmitter release. Life Sci 56: 571-577.

Gordon M (1983). Gordon Diagnostic Systems. Gordon Systems: DeWitt, NY.

Grant KA, Lovinger DM (1995). Cellular and behavioral neurobiology of alcohol: receptor-mediated neuronal processes. Clin Neurosci 3: 155-164.

Hariharan M, Naga S, VanNoord T (1993). Systematic approach to the development of plasma amino acid analysis by highperformance liquid chromatography with ultraviolet detection with precolumn derivatization using phenyl isothiocyanate. J Chromatogr 621: 15-22.

Hoffman PL (2003). NMDA receptors in alcoholism. Int Rev Neurobiol 56: 35-82.

Hoffman PL, Grant KA, Snell LD, Reinlib L, Iorio K, Tabakoff B (1992). NMDA receptors: role in ethanol withdrawal seizures. Ann N Y Acad Sci 654: 52-60.

Hood WF, Compton RP, Monahan JB (1989). -Cycloserine: a ligand for the $N$-methyl-D-aspartate coupled glycine receptor has partial agonist characteristics. Neurosci Lett 98: 91-95.

Koller G, Zill P, Fehr C, Pogarell O, Bondy B, Soyka M et al (2009). No association of alcohol dependence with SLC6A5 and SLC6A9 glycine transporter polymorphisms. Addict Biol 14: 506-508.

Kostowski W, Bienkowski P (1999). Discriminative stimulus effects of ethanol: neuropharmacological characterization. Alcohol 17: 63-80.

Kotlinska J, Liljequist S (1997). The NMDA/glycine receptor antagonist, L-701,324, produces discriminative stimuli similar to those of ethanol. Eur J Pharmacol 332: 1-8.

Krueger JM, O'Connor AJ, Kelso SR (1997). Glycine site agonists exhibit subunit specific effects on NMDA receptors expressed in Xenopus oocytes. Soc Neurosci Abstr 23: 945.

Krupitsky EM, Neznanova O, Masalov D, Burakov AM, Didenko T, Romanova $\mathrm{T}$ et al (2007a). Effect of memantine on cue-induced alcohol craving in recovering alcohol-dependent patients. Am J Psychiatry 164: 519-523.

Krupitsky EM, Rudenko AA, Burakov AM, Slavina TY, Grinenko AA, Pittman B et al (2007b). Antiglutamatergic strategies for ethanol detoxification: comparison with placebo and diazepam. Alcohol Clin Exp Res 31: 604-611.

Krystal J, Petrakis I, Krasnicki S, Trevisan L, Boutros N, D’Souza DC (1998a). Altered responses to agonists of the strychnineinsensitive glycine NMDA coagonist (SIGLY) site in recently detoxified alcoholics. Alcohol Clin Exp Res 22: 94A.

Krystal JH, Petrakis IL, Limoncelli D, Webb E, Gueorgueva R, D'Souza DC et al (2003a). Altered NMDA glutamate receptor antagonist response in recovering ethanol-dependent patients. Neuropsychopharmacology 28: 2020-2028.

Krystal JH, Petrakis IL, Mason G, D'Souza DC (2003b). NMDA glutamate receptors and alcoholism: reward, dependence, treatment, and vulnerability. Pharmacol Therap 99: 79-94.

Krystal JH, Petrakis IL, Trevisan L, D'Souza DC (2003c). NMDA receptor antagonism and the ethanol intoxication signal: from alcoholism risk to pharmacotherapy. Ann N Y Acad Sci 1003: 176-184.

Krystal JH, Petrakis IL, Webb E, Cooney NL, Karper LP, Namanworth S et al (1998b). Dose-related ethanol-like effects of the NMDA antagonist, ketamine, in recently detoxified alcoholics. Arch Gen Psychiatry 55: 354-360.

Krystal JH, Petrakis IL, Webb E, Cooney NL, Karper LP, Namanworth S et al (1998c). Dose-related ethanol-like effects of the NMDA antagonist, ketamine, in recently detoxified alcoholics. Arch Gen Psychiatry 55: 354-360.

Krystal JH, Webb E, Cooney N, Kranzler HR, Charney DS (1994). Specificity of ethanol like effects elicited by serotonergic and noradrenergic mechanisms. Archiv Gen Psychiatry 51: 898-911.

Kumari M, Ticku MK (2000). Regulation of NMDA receptors by ethanol. Progr Drug Res 54: 151-189.

Lido HH, Stomberg R, Fagerberg A, Ericson M, Soderpalm B (2009). The glycine reuptake inhibitor org 25935 interacts with basal and ethanol-induced dopamine release in rat nucleus accumbens. Alcohol Clin Exp Res 33: 1151-1157.

Martin CS, Earleywine M, Musty RE, Perrine MW, Swift RM (1993). Development and validation of the Biphasic Alcohol Effects Scale. Alcohol Clin Exp Res 17: 140-146.

Molander A, Lido HH, Lof E, Ericson M, Soderpalm B (2007). The glycine reuptake inhibitor Org 25935 decreases ethanol intake and preference in male wistar rats. Alcohol Alcohol 42: $11-18$.

Morgan CJ, Perry EB, Cho HS, Krystal JH, D’Souza DC (2006). Greater vulnerability to the amnestic effects of ketamine in males. Psychopharmacology (Berl) 187: 405-414.

Petrakis IL, Limoncelli D, Gueorguieva R, Jatlow P, Boutros NN, Trevisan L et al (2004). Altered NMDA glutamate receptor antagonist response in individuals with a family vulnerability to alcoholism. Am J Psychiatry 161: 1776-1782.

Rammes G, Mahal B, Putzke J, Parsons C, Spielmanns P, Pestel E et al (2001). The anti-craving compound acamprosate acts as a weak NMDA-receptor antagonist, but modulates NMDAreceptor subunit expression similar to memantine and MK-801. Neuropharmacology 40: 749-760.

Schutz CG, Soyka M (2000). Dextromethorphan challenge in alcohol-dependent patients and controls. Arch Gen Psychiatry 57: 291-292.

Sheinin A, Shavit S, Benveniste M (2001). Subunit specificity and mechanism of action of NMDA partial agonist D-cycloserine. Neuropharmacology 41: 151-158.

Spitzer RL, Williams JB, Gibbon M, First MB (1992). The Structured Clinical Interview for DSM-III-R (SCID). I: History, rationale, and description. Arch Gen Psychiatry 49: 624-629.

Spitzer RL, Williams JBW, Gibbon M, First MB (1990). Structured Clinical Interview for DSM-III-R-Nan-Patient Edition (SCID-NP, Version 1.0 with supplement for DSM-IV). American Psychiatric Press: Washington, D.C..

Stern RA, Silva SG, Chaisson N, Evans DL (1996). Influence of cognitive reserve on neuropsychological functioning in asymptomatic human immunodeficiency virus-1 infection. Arch Neurol 53: $148-153$.

Trevisan L, Petrakis IL, Pittman B, Gueorguieva R, D'Souza DC, Perry E et al (2008). Absence of significant interactive effects of high-dose D-cycloserine and ethanol in healthy human subjects: preliminary insights into ethanol actions at the glycine(B) site of NMDA glutamate receptors. Alcohol Clin Exp Res 32: 36-42.

von Knorring AL, Bohman M, von Knorring L, Oreland L (1985). Platelet MAO activity as a biological marker in subgroups of alcoholism. Acta Psychiatr Scand 72: 51-58.

Watson GB, Bolanowski MA, Baganoff MP, Deppeler CL, Lanthorn TH (1990). -Cycloserine acts as a partial agonist at the glycine modulatory site of the NMDA receptor expressed in Xenopus oocytes. Brain Res 510: 158-160.

Witkin JM, Brave S, French D, Geter-Douglass B (1995). Discriminative stimulus effects of $R-(+)-3$-amino-1-hydroxypyrrolid-2-one, [(+)-HA-966], a partial agonist of the strychnine-insensitive modulatory site of the $N$-methyl-D-aspartate receptor. J Pharmacol Exp Ther 275: 1267-1273. 